\title{
Phytochemical and Antibacterial Screening of the Leaf Extracts of Bombax buonopozense
}

\author{
K Abdu*, H Ammani \\ Department of Pure and Industrial Chemistry, Bayero University, Kano, Nigeria
}

"Corresponding author: KAbdu, Department of Pure and Industrial Chemistry, Bayero University, Kano, Nigeria. Tel: +23464666023; Fax:+23464661480; Email: kabdu.chm@buk.edu.ng

Citation: Abdu K, Ammani H (2017) Phytochemical and Antibacterial Screening of the Leaf Extracts of Bombax buonopozense. J Pharma Pharma Sci: JPPS-120. DOI:10.29011/2574-7711/100020

Received Date: 21 March, 2017; Accepted Date: 23 March, 2017; Published Date: 30 March, 2017

\begin{abstract}
Fresh powdered leaves $(200 \mathrm{~g})$ of Bombax buonopozensewas percolated with $95 \%$ ethanol $(1000 \mathrm{~cm} 3)$ for one week. It was decanted, filtered and evaporated on rota vapor (R110) at 40oC to obtained the crude ethanol extract (F1). It was macerated sequentially with chloroform, ethyl acetate, acetone and water to obtained the chloroform soluble fraction (F2), ethyl acetate soluble fraction (F3), acetone soluble fraction (F4) and water soluble fraction (F5) respectively. All the five fractions were subjected to phytochemical screening to check the presence of some secondary metabolites, also antibacterial screening was carried out against some clinical isolates. Presence of alkaloids, flavonoids, phenolic glycoside, tannins, saponins and anthraquinones were detected in all/ some of the tested fractions. Also a remarkable zones of inhibition on some of the baterial isolates by some fractions were recorded.
\end{abstract}

Keywords: Antibacteria; Inhibition; Isolates; Maceration; Phytochemical

\section{Introduction}

Bombax buonopozense is a large tropical tree that grows up to 40 metres in height with large buttress roots that can spread 6 metresdown [1]. The individual leaf has entire margin and quite large, measuring from 8 to $23 \mathrm{~cm}$ in length by 3 to $7.5 \mathrm{~cm}$ in width with the under sides of the leaf being conical buds which contains many seeds that are 5 to $6 \mathrm{~mm}$ in length, all of which have a cotton-like fibre covering [2]. B. buonopozenseis called 'Akpu' in Igbo, 'Kurya' in Hausa and 'Ogbolo' in Yoruba. Different parts of the plant are used for different purposes [3]. The edible floral part of the plant is used as vegetable by the inhabitants of North Central Nigeria and is used as medicine due to its nutritive and therapeutic properties [1].The plant is widely distributed in West African countries such as Ghana [4]and,[5], Gambia, Côte d'Ivoire [6], Nigeria[1] and others. Hot decoction of the dried stem bark of the plant is taken orallyfor the treatment of malaria in Ghana [7]. The bark is used to treat chest pain in Gambia [8]. Decoction of the leaves is used to manage stomach ulcers and burns in Ghana. Aqueous extract of the leaves is claimed to be effective in the treatment of diarrhea and dysentery [9]. The immature fruits are prepared as an emollient for skin, decoction of the young leaves is used as a warm bath for febrile children. The grounded bark is taken by pregnant women to increase lactation; the extract from the bark is drunk or applied on the head for dizziness. The gum resin from the bark is pulverized, mixed with oil and used to manage skin diseases [10].

The study was set to investigate and identified the phytochemical agents present in the leaf extracts and to carry out the in vitro evaluation of the antibacterial activity of the extracts against some selected pathogens.

\section{Materials and Methods}

\section{Plant Collection}

Fresh leaves of B. buonopozense were collected from Dankama Kaita local Government Area, Katsina State. It was identified and authenticated by Dr. Nuhu Yusuf of Plant Sciences Department, Bayero University Kano. It was then air dried before it was ground into powder using mortar and pistil.

\section{Extraction}

Two hundred grams $(200 \mathrm{~g})$ of the powdered leaves was percolated with $1000 \mathrm{~cm}^{3}$ ofabsolute ethanol for one week [11]. 
The extract was decanted, filtered and evaporated using rotary evaporator (R110) at $40^{\circ} \mathrm{C}$ to obtain the crude ethanol extract which was labeled as $\mathrm{F}_{1}$ and kept in a refrigerator at $0^{\circ} \mathrm{C}$ before used.

\section{Macerationof Crude Ethanol Extracts $\left(F_{1}\right)$}

The crude ethanol extract, $F_{1}$ was macerated with $400 \mathrm{~cm}^{3}$ of chloroformin parts using $100 \mathrm{~cm}^{3}$ each, four times to get the chloroform soluble fraction $\left(\mathrm{F}_{2}\right)$.The insoluble fraction was also macerated with $400 \mathrm{~cm}^{3}$ of ethyl acetate in parts using $100 \mathrm{~cm}^{3}$ each,four times to get ethyl acetate soluble fraction $\left(\mathrm{F}_{3}\right)$. The ethyl acetate insoluble residue was also macerated with $400 \mathrm{~cm}^{3}$ of acetone in parts using $100 \mathrm{~cm}^{3}$ each,four times to get the acetone soluble fraction $\left(\mathrm{F}_{4}\right)$. The acetone insoluble residue was dissolved in distilled water to give the water soluble fraction $\left(\mathrm{F}_{5}\right)$.

\section{Phytochemical Screening}

All the fractions $\left(\mathrm{F}_{1}\right.$ to $\left.\mathrm{F}_{5}\right)$ were subjected to phytochemical screening, to determine the types of secondary metabolites present in the different fractions. These include phenolic glycocides, alkaloids, anthraquinones, saponins, tannins and flavonoids.

\section{Test for Alkaloids}

Each fraction $(0.5 \mathrm{~g})$ was dissolved in $5 \mathrm{~cm}^{3}$ of $1 \% \mathrm{HCl}$ inside a test tube on a steam bath. The solution was cooled down before it was filtered. An aliquot of the filtrate $\left(1 \mathrm{~cm}^{3}\right)$ was treated with 2-3 drops of Dragendoffs reagent. The result was observed and reported.

\section{Test for Flavonoids}

Each fraction $(0.5 \mathrm{~g})$ was dissolved in $2 \mathrm{~cm}^{3}$ of $50 \%$ methanol by heating inside a test tube. Magnesium metal $(10 \mathrm{mg})$ and concentrated hydrochloric acid 50\% (5-6 drops) were added (Sofowora, 1993)[12]. The result was observed and reported.

\section{Test for Phenolic Glycosides}

2-3 drops of each fraction was added to few drops of sulfuric acid in a boiling tube.The result was observed and reported.

\section{Test for Anthraquinone}

Each fraction $\left(2 \mathrm{~cm}^{3}\right)$ was boiled with $1 \mathrm{~cm}^{3}$ of dilute sulphuric acid for $5 \mathrm{~min}$ and then filtered while hot. The filtrate was cooled down and shaken with equal volume of dichloromethane. The dichloromethane layer was then separated and shaken with about $3 \mathrm{~cm}^{3}$ of dilute ammonia. The result was observed and reported.

\section{Test for Tannin}

Each fraction $\left(2 \mathrm{~cm}^{3}\right)$ was treated with 3 drops of $5 \%$ $\mathrm{FeCl}_{3}[13]$. The result was observed and reported.

\section{Test for Saponins}

Each fraction $\left(2 \mathrm{~cm}^{3}\right)$ was vigorously shaken with distilled water and allowed to stand for a while [12]. The result was observed and reported.

\section{Antibacterial Bioassay}

\section{Preparation of Test Solution and Disc Concentration}

The extracts were dissolved using DiMethyl SulphOxide (DMSO).The stock solutions were prepared by dissolving 0.06 $\mathrm{mg}$ of each fraction in $1 \mathrm{~cm}^{3}$ of the solvent. For each fraction concentrations of $60 \mu \mathrm{g} / \mathrm{disc}, 30 \mu \mathrm{g} / \mathrm{disc}$, and $15 \mu \mathrm{g} / \mathrm{disc}$ were prepared separately in sterilized Bijour bottles containing 50 sterile improvised what man filter paper.The filter papers were saturated (impregnated) with plant extract of desired concentration. The serial dilution was carried out as follows:

Concentration of $60 \mu \mathrm{g} /$ disc: From the stock solution, $0.5 \mathrm{~cm}^{3}$ was taken into a Bijour bottle containing the discs and labeled $60 \mu \mathrm{g} / \mathrm{disc}$.

Concentration of $30 \mu \mathrm{g} / \mathrm{disc}: 0.5 \mathrm{~cm}^{3}$ of DMSO was added into the remaining $0.5 \mathrm{~cm}^{3}$ of the stock solution making $1 \mathrm{~cm}^{3}$. It was divided into two and half of it $\left(0.5 \mathrm{~cm}^{3}\right)$ was taken into another Bijour bottle containing the discs and was labeled $30 \mu \mathrm{g} / \mathrm{disc}$.

Concentration of $15 \mu \mathrm{g} /$ disc: to the remaining $0.5 \mathrm{~cm}^{3}$ of $30 \mu \mathrm{g} /$ disc solution, $0.5 \mathrm{~cm}^{3}$ DMSO was added tomake it $1 \mathrm{~cm}^{3}$. It was also divided into two and half $\left(0.5 \mathrm{~cm}^{3}\right)$ of it was taken into another Bijour bottle containing the discs and labeled $15 \mu \mathrm{g} / \mathrm{disc}$.

\section{Inoculums Standardization}

As described by standard sensitivity test National Committee for Clinical Laboratory Standards(NCCLS)[14], loops of the confirmed isolates were introduced in peptone water in separate sterilized bottles and kept overnight in an incubator $\left(37^{\circ} \mathrm{C}\right)$. Few colonies of the overnight growth of the isolates to be tested were dispersed in sterile normal saline to form a turbid culture suspension that match $0.5 \mathrm{McF}$ arland turbidity.

\section{Preparation of Media}

Nutrient agar $(28 \mathrm{~g})$ was dissolved in $1000 \mathrm{~cm}^{3}$ of distilled water, as per manufacturer's instructions. The conical flask containing the nutrient agar solution was autoclaved for 15 minutes at $121^{\circ} \mathrm{C} \cdot 20-25 \mathrm{~cm}^{3}$ of the sterilized nutrient agar was transferred into petri-dishes under septic condition. The petri-dishes were allowed to cool and solidify.

\section{In vitro Antibacterial Susceptibility Test}

Antibacterial activities of the extracts were determined using disc diffusion method of Antimicrobial Susceptibility Test (AST) as described by (NCCLS, 2000). Standardized inocula of the isolates were swabbed onto the surface of the solidified and oven-dried nutrient agar in separate petri-dishes under sterilized environment. The four prepared discs of the different concentrations of the extracts were then placed onto the surface of the inoculated media 
at intervals in a clockwise direction. The positive control discs were placed at the center of the bacteria inoculated medium. The plates were incubated for 24 hours at $37^{\circ} \mathrm{C}$ for bacteria cultures, after which the antibacterial activity was observed by measuring the width of the clear zones of inhibition around the discs and the values obtained recorded.

\section{Results and Discussion}

The results for extraction using percolation and maceration with different solvents of different polarity were given in (Table 1) below.

\begin{tabular}{|c|c|c|c|}
\hline Fraction & Texture & Colour & Weight (g) \\
\hline Crude ethanol extract (F1) & Gummy & Black & 37.39 \\
\hline Choloroform fraction (F2) & Gummy & Black & 3.07 \\
\hline Ethyl acetate fraction (F3) & Gummy & Black & 2.09 \\
\hline Acetone fraction (F4) & Gummy & Dark brown & 1.58 \\
\hline Aqueous fraction (F5) & Gummy & Brown & 10.8 \\
\hline
\end{tabular}

Table 1: Extraction results with the physical properties of the extracts.

Phytochemical screening was carried out which involves the tests for alkaloids, flavonoids, phenolic glycosides, anthraquinones, tannins and saponins. The crude ethanol extract (F1), acetone fraction (F4) and the aqueous fraction (F5) were found to contain all the tested secondary metabolite. The chloroform fraction (F2) also contains all the tested secondary metabolites except phenolic glycosides. While the ethyl acetate fraction (F3) was found to contains only phenolic glycosides, anthraquinones and alkaloids. All the fractions (F1-F5) were found to form an orange red precipitate/ turbidity when treated with Draggendoff's reagent which indicates the presence of alkaloids [15]. Similarly, all the fractions give a reddish-pink colour when treated with ammonia which confirmed the presence of anthraquinones in all the fractions [12]. Fractions F1, F2, F4 and F5 show the appearance of a red colour when treated with conc. $\mathrm{HCl}$ which indicates the presence of flavonoids [12]. Similarly, fractions F1, F2, F4 and F5 gives a dark black coloured precipitate with ferric chloride which turned green-black to blueblack colouration on dilution which indicates the presence of tannins [13]. Also fractions F1, F2, F4 and F5 shows a persistent frothing when shaken with distilled water which indicates the presence of saponins [12]. Fractions F1, F3, F4 and F5 were found to show a red colouration which disappeared upon addition of distilled water which confirmed the presence of phenolic glycoside. The results were shown in Table 2 below.

The antimicrobial activity of the different fractions of $B$. buonopozenes was investigated against some pathogens.Some fractions were found to possess the bioactivity against some of the tested microorganisms. The tested organisms includeKlebsiella spp., Pseudomonas auriginosa, Proteus spp., E.coliand Staphylococcus aureus. The crude ethanol extract exhibited the highest activity on all the tested pathogens at all concentrations, but with highest inhibition on E. coli and Klebsiella spp.both at the concentration of $60 \mu \mathrm{gml}^{-1}$. It was followed by chloroform fraction which showed remarkable zones of inhibition on E. coli, Klebsiella spp., Pseudomonas auriginosa and Proteus spp.but with highest inhibition on E. coli andPseudomonas auriginosaat concentration of $60 \mu \mathrm{g} \mathrm{ml}^{-1}$. The fraction with least activities was found to be aqueous fraction which exhibited low activity on Kebsiellaspp.,Pseudomonas auriginosa and E. coli (Table 3).

\begin{tabular}{|l|l|l|l|l|l|}
\hline Secondary Metabolites & F1 & F2 & F3 & F4 & F5 \\
\hline Phenolicgylcosides & + & - & + & + & + \\
\hline Anthraquinones & + & + & + & + & + \\
\hline Flavonoids & + & + & - & + & + \\
\hline Tannins & + & + & - & + & + \\
\hline Saponins & + & + & - & + & + \\
\hline Alkaloids & + & + & + & + & + \\
\hline \multicolumn{7}{|l|}{ Keys: '+' indicate presence, '-'indicate absence. } \\
\hline
\end{tabular}

Table 2: Results of the phytochemical screening.

\begin{tabular}{|c|c|c|c|c|c|c|c|c|c|c|c|c|c|c|c|c|}
\hline \multicolumn{17}{|c|}{ Zones of Inhibition $(\mathrm{mm})$ at different concentrations in $\mu \mathrm{g} / \mathrm{mL}$} \\
\hline \multirow{2}{*}{ Pathogens } & \multicolumn{3}{|c|}{$\mathbf{F}_{1}$} & \multicolumn{3}{|c|}{$\mathbf{F}_{2}$} & \multicolumn{3}{|c|}{$F_{3}$} & \multicolumn{3}{|c|}{$\mathbf{F}_{4}$} & \multicolumn{3}{|c|}{$F_{5}$} & \multirow{2}{*}{$\frac{\text { AUG }}{(30 \mu \mathrm{g})}$} \\
\hline & 60 & 30 & 15 & 60 & 30 & 15 & 60 & 30 & 15 & 60 & 30 & 15 & 60 & 30 & 15 & \\
\hline Klebsiellaspp. & 12 & 10 & 8 & 9 & 8 & 6 & 9 & 7 & - & - & - & - & 8 & 7 & 6 & 23 \\
\hline Pseudomonas auriginosa & 10 & 9 & 9 & 10 & 9 & 7 & 8 & 7 & 6 & 8 & 6 & - & 8 & 7 & 6 & 30 \\
\hline Proteusspp. & 9 & 8 & 7 & 7 & 6 & - & - & - & - & 10 & 8 & 7 & - & - & - & 16 \\
\hline E.coli & 13 & 11 & 10 & 12 & 10 & 9 & 9 & 8 & 7 & 10 & 8 & 7 & 9 & 7 & - & 33 \\
\hline Staphylococci. aureus & 9 & 7 & 6 & - & - & - & 7 & 6 & - & 8 & 6 & - & - & - & - & 27 \\
\hline & & & & & : $\mathbf{A U}$ & $=A$ & nenti & stanc & & & & & & & & \\
\hline
\end{tabular}

Table 3: Antibacterial screening results. 
Phytochemical analysis of the plants revealed the presence of alkaloids, phenolic glycosides, anthraquinoes, Flavonoids, tannins and saponins. From the results, the leaf extracts of the plant were found to show a significant level antibacterial activity. The revealed secondary metabolites are known to be biologically active and thus aid the antibacterial activities of B. buonopozense. Phytochemicals exert antimicrobial activity through different modes of action.For example,tannins act by hydrogen deprivation, hydrogen bonding or specific interactions with vital proteins such as enzymes in microbial cells [16]. Alkaloids have been associated with medicinal uses for centuries. One of the most common biological properties of alkaloids is their toxicity against cells of foreign organisms. Flavonoids also exhibit a wide range of biological activities such as antimicrobial, anti-inflammatory, analgesic, hypoglycemic and antioxidant properties [17]. They have the ability of scavenging hydroxyl radicals, superoxide anion radicals and lipid peroxy-radicals which are important for prevention of diseases associated with oxidative damage of membrane, proteins and DNA [18]. Saponins are considered as a key ingredient in Chinese medicine and are responsible for most of the observed biological activity [19]. They are known to produce inhibitory effect on inflammation [20]. Therefore, the presence of these phytochemical in the plant strongly aided the antibacterial activity observed.

\section{Conclusion}

Extraction of the leaves of Bombax buonopozense was successfully carried out by maceration using solvent of different polarities. Phytochemical screening of the extract revealed the presence of many secondary metabolites which are believed to be responsible for antibacterial activity observed.The results supported the traditional usefulness of Bombax buonopozenese as a medical remedy for some illnesses.

\section{References}

1. Mann A, Gbate M,Nda-Umar A (2003) Medicinal and Economic plants of Nupe land. Jube-Evans Books and publications, Bida Nigeria 3536.

2. Beentje H,Sara S (2001) Plant Systematic and Phytogeography for the understanding of African Biodiversity, Systematic and Geography of plants $71: 284-286$.

3. Dubost G,Gabon J (1984) Comparison of Diets of frugivorous forest mammals 65: 298-316.

4. Addo-Fordjour P, Obeng S, Addo MG, Akyeampong S (2009) Effects of human disturbances and plant invasion on Liana community structure and relationship with trees in the Tinte Bepo Forest Reserve, Ghana. Fonnr Manage 258: 728-734.
5. Gyasi E. Agyepong G. Ardayfio-Schandorf E, Enu-Kwesi L, Nabila J,et al. (1995) Production pressure and environmental change in the forestsavanna zone of Southern Ghana. Glob Environ Chang 5: 355-366.

6. Kamanzi, Atindehou K, Schmid C, Brun R, Koné MW,et al. (2004) Antitrypanosomal and antiplasmodial activity of medicinal plants from Côte d'ivoire. J Ethnopharmacol 90: 221-227.

7. Asase A, Oppong-Mensah G (2009)Traditional antimalarial phytotherapy remedies in herbal markets in Southern Ghana. J Ethnopharmacol126: 492-499.

8. Madge C (1998) Therapeutic landscapes of the Jola, the Gambia, and West Africa. Health Place4: 293-311.

9. Irvine FR (1961) Woody plants of Ghana (1). Oxford University Publishers, London 897-955.

10. Insoll T (2007) 'Natural' or 'human' spaces? Tallensi sacred groves and shrines and their potential implications for aspects of northern European prehistory and phenomenological interpretation. Nor Archaeol 40: 138.

11. Abdu K, Echeme JO (2006) Phytochemical and Antimicrobial Screening of the Ethanolic Extract of the Leaves of Anogeissus leiocarpus. BEST 3: $162-164$

12. Sofowora A (1993) Medicinal plant and traditional medicine in Africa. Spectrum Books Itd (Ibadan) 142-144.

13. Harbone JB (1998) Phytochemical Methods, Chapman and Halls: London 91.

14. National Committee for Clinical Laboratory Standards (2008) Performance Standards for Antimicrobial Testing, Wayne PA.

15. Evans WC (2002) Trease and Evans Pharmacognosy, (15th edn). BailliereTindall: London 253: 289- 333.

16. Alma MH, Mavi A, Yildirim A, Digrak M, Hirata $T(2003)$ Screening chemical composition and in vitro antioxidants and antimicrobial activities of the essential oils from the Origanumsyriacum L. growing in Turkey. Biol Pharm Bull 26: 1735-1739.

17. El Astal ZY, Aera A,Aam A (2005) Antimicrobial activity of some medicinal plant extracts in Palestiine. Pak J Med Sci 21: 187.

18. Godwin Akuodor C, Augustine Essien D, Jemilat Ibrahim A, Augustine Bassey, Joseph Akpan L, et al. (2011)Phytochemical and antimicrobial properties of the methanolic extracts of Bombax buonopozenseleaf and root, As J Med Sci 2: 190-194.

19. Mann A, Salawu FB,Abdulrauf I (2011) Antimicrobial activity of Bombax buonopozense. Beav. (Bombacaceae) edible floral extracts. Eur J Sci 48:627-630.

20. Gupta, Oliver-Bever B (1983) Medicinal plants in tropical West Africa III. Anti-infection therapy with higher plants. J Ethnopharmacol 9: 1-83. 